\title{
Chapter 4: Agile Approach to e-HRM Project Management
}

\section{NMK Bhatta \& Mohan Thite}

\begin{abstract}
In an uncertain, fast changing and hyper competitive business environment, Agility, characterised by innovative and self-managing teams, learning organisation environment and customer-driven process is the key. This chapter introduces the philosophy and principles underpinning Agile way of working in software development. It specifically highlights the critical role played by HR in attracting, developing and retaining talent that befits the overarching Agile philosophy. It also identifies the implementation challenges and success
\end{abstract} factors.

\section{Learning Objectives}

- Explain the Agile Manifesto and its key characteristics and principles

- Present the process map of and the key terms used in Agile Scrum Method

- Discuss how HR can play a transformative role in implementing Agile with specific reference to organisational culture, recruitment and selection and performance and reward management.

- Highlight the key components of the HR->T Talent Management Model

- Critically present the major implementation challenges in implementing Agile

\section{Introduction}

"If software has eaten the world, then agile has eaten the software world" (Gothelf, 2017).

In the previous chapter, we introduced the soft systems thinking approach and systems development life cycle (SDLC) framework as critical starting points for e-HRM project management. The waterfall methodology in the SDLC is a sequential approach where the project team goes to the next phase only after completely satisfied with the previous phase. The development work is broken down into small parts and distributed to teams based on their skills. The customer gets involved only later at the testing stage and further guides the process to completion. 
The waterfall approach is particularly suitable for well-defined and well scoped projects with pre-determined processes and comprehensive documentation. The rigidity in the system is supposed to keep the scope, costs and schedule well under control. However, in a business environment that is rapidly and radically changing, due to globalisation and disruptive technologies resulting in hyper-competitive market conditions, technology project teams require agility not rigidity in the way the project is executed.

The alarmingly high failure rate of technology projects as detailed in the previous chapter made software engineers across the world to pause and rethink if the traditional methods of project management were suitable for all types of projects and all business situations. Their analysis revealed that the project management approach that they were hitherto following would work only when all the requirements of the customer are very clearly known and frozen upfront at the very beginning of the project. In an ever changing and dynamic business scenario where competitive pressures and technological advances compel businesses to continually reassess their requirements, the traditional approaches may not be suitable.

The analysis also found that the methodologies that they were following were too process oriented with little scope for creativity or out of the box thinking. Customers' perceived value addition was also low because with the conventional methods of IT project management, they had very little opportunity to preview the system till the end by when it was too late to make major changes. While the traditional waterfall methods can be continued for projects having absolute clarity of requirements with no changes expected, for other projects with stringent Go To Market constraints or with vague/unclear requirements, we need a completely new thinking of IT Project Management based on the principles of agility, transparency and adaptation and more active customer involvement. Thus, began a new philosophy called Agile Project Management with the release of an Agile Manifesto in 2001.

The agile philosophy has been rapidly gaining prominence in recent times and has had a huge impact on how software is developed worldwide' (Dyba \& Dingsoyr, 2008, p. 834) and in the process 'revolutionised information technology' (Rigby, Sutherland \& Takeuchi, 2016). In this methodology the developmental life cycle is divided into smaller parts, called 'increments' or 'iterations' wherein the phases within the life cycle are visited repeatedly in order to incrementally and iteratively improve the project outcomes. According to Leau, Loo, Tham \& Tan (2012, p. 163-164), 
"Agile methods emphasize on teams, working software, customer collaboration, and responding to change; while the conventional methods stress on contracts, plans, processes, documents, and tools ... Taking the fact that customers' requirements are acquired iteratively as context, agile development is able to deliver an end-product that better meets customer needs".

According to the $10^{\text {th }}$ Annual State of Agile Report (VersionOne, 2016), increasingly larger organisations around the world are embracing Agile which is helping them to drive business success with continued positive impact. The Standish Group 2015 Chaos Report (Hastie \& Wojewoda, 2015) also confirms that "across all project sizes agile approaches resulted in more successful projects and less outright failures".

In this chapter we will introduce the philosophy, principles and characteristics of the agile approach, with specific reference to scrum process. We will then highlight the critical role played by HR as a change agent and facilitator of the Agile journey and how it can reengineer the talent management tools and techniques to attract, assess, develop and reward talent. We will conclude with the implementation challenges and success factors.

\section{Agile Manifesto \& Principles}

Agile software development methods took birth with the release of Agile Manifesto in 2001 (Agilemanifesto.org) which states as below:

"We are uncovering better ways of developing software by doing it and helping others do it. Through this work, we have come to value

Individuals and interactions over processes and tools

Working software over comprehensive documentation

\section{Customer collaboration over contract negotiation}

\section{Responding to change over following a plan}

That is, while there is value in the items on the right, we value the items on the left more."

Agile Manifesto puts self-organisation and team dynamics above a pre-determined and rigid set of processes or tools. A code which works is more useful than extensive documentation presented to the customer. Since requirements can never be fully finalised up front for many projects, continuous customer participation in the software development is vital. A typical 
software project requirement can never be frozen and therefore, the ability of the project team to accept the changes at all stages will be critical for expected customer value creation.

Conventional methods may still be used where there is complete clarity on project requirements and they are fully stable. A vast number of companies still use conventional methods. But if there is any vagueness or incomplete requirements, Agile methods provide an answer. Many companies in fact combine conventional and Agile methods in a new series of methods called Hybrid Agile (which is out of scope for this chapter).

While several versions of Agile have been introduced after the release of Agile Manifesto in 2001, all of them are built on the basic premise that people contribute their best when they have autonomy in decision making. Group dynamics and human psychology take centre stage in Agile. This calls for more focussed and innovative HR support for Agile projects with the HR ecosystem conforming to Agile principles and manifesto.

The Agile manifesto is underpinned by 12 Agile principles as outlined in Table 4.1.

Insert Table 4.1 somewhere here

\section{Key Characteristics of Agile Methods}

The following characteristics define the fabric of all agile methods

- Self-Organising and Cross Functional Teams: In Agile, the project team is completely empowered and assumes authority over all technical and managerial matters. Each team features cross functional members so that they can meet the project objectives without any external help.

- Time-boxed Iterations: All Agile methods stipulate that at the end of every fixed time interval (called a time-boxed iteration) some tangible pre-determined, potentially shippable delivery is made to the customer conforming to some shared definition.

- Fully Participating Customer: Agile methods argue that customer should have a final say on what work should be carried out by the team and the team should have a final say on how that work will be carried out. It also insists on full time availability of the customer for the team to seek any clarifications and to finally inspect team's output at the end of each time-boxed iteration. 
- Minimal Documentation: In Agile, emphasis is more on working software and documentation is reduced to bare minimum as agreed between the customer and the team.

- Collective/ Multiple Ownership: In Agile, the entire team takes the ownership of the deliverables collectively. This also gives a chance to every member of the team to review or improve the work done by any other team member. This helps in making full use of the team capabilities and competencies.

- Rapid Feedback and Action: Agile facilitates inspect output at the end of every iteration by the customer and the same is considered closed if it conforms to pre-decided Definition. Any further changes or improvements are handled as new requirements in subsequent iterations.

- Servant Leadership: While teams in Agile are entirely self-organised and cross functional, it still has scope for one person to act as servant leader of the team. Such a member is called as Scrum Master in Scrum method of Agile. Scrum Master has a role of protecting the team members from external interferences, resolving various problems (technical or otherwise) faced by the team members and to ensure that the team follows all agile practices meticulously. However, he/she is not expected to manage the day-today working of the team. It is also possible that one of the team members assumes an additional charge of scrum master.

- Retrospection and Openness to Criticism: Agile believes that at the end of each iteration, the team and the customer retrospect on what went well during the iteration, what did not go well and how the subsequent iterations can be improved. Here, every stakeholder will be open to criticism by the other stakeholders on his/her performance during the iteration. While the entire retrospection is carried out with an objective of avoiding similar issues in future iterations, it still calls for tremendous maturity on the part of the members to have an open mind to constructive criticism.

- Complete Transparency: The teams in Agile work in an environment of complete transparency. All team members and the customers are always aware of what each member has done, is doing and will be doing. Added to this, every team member is required to explain what he/she has done, will be doing and the impediments/ challenges faced every day in a meeting called Daily Stand-up Meeting. This increases accountability and ownership on the part of team members. 


\section{Agile Scrum Methodology}

There are several Agile methods in use. According to the $10^{\text {th }}$ Annual State of Agile Report, (Versionone.com, 2016), 58\% of Agile users are using pure Scrum and $17 \%$ are using a combination of Scrum with other methods. Rest of the users adopt other Agile methods, including, Kanban, Feature Driven Development, Lean, and Extreme Programming. However, the core principles underlying all the methods are the same and are derived from the Agile Manifesto. As Burchardi et al. (2016, p. 2) emphasise "many forms of Agile have been developed, but at its heart, Agile is a set of beliefs. It is iterative, empirical, crossfunctional, focused, and continually improving".

\section{Scrum Process}

Scrum is an Agile method with three major stakeholders, namely, Product Owner (PO), Scrum Master (SM) and the Development Team. Work is done in a series of time-boxed iterations called Sprints (which typically lasts for 1-4 weeks). Product Owner owns a prioritised list of requirements called Product Backlog and decides what work should be carried out. The development team decides how much can be done in each sprint and how it will be done. Scrum Master helps both the PO and the team in following scrum process and removing any obstacles on the way.

Figure 4.1 presents the Agile Scrum Process Diagram.

Insert Figure 4.1 somewhere here

Before every sprint, a Sprint Planning Meeting is conducted, where the work is broken down into tasks and the team distributes these tasks among themselves. A list of all these tasks is called Sprint Backlog. During each Sprint, the team conducts a daily stand-up meeting every day to explain each other on what has been done, what will be done and what are the obstacles. At the end of The Sprint, the team presents its output (which is called a potentially shippable product) to all stakeholders including some business users. After Sprint Review, PO, SM and the Development Team conduct a Sprint Retrospective Meeting to retrospect on what went well in the sprint, what didn't go well and what can be improved in the upcoming 
sprints. Process is continued sprint after sprint till the final product is released to the customer.

Table 4.2 summarises the key terms used in Agile Scrum.

Insert Table 4.2 somewhere here

\section{Role of HR in Agile}

Traditionally, HR has generally played a support role in e-HRM project management, mostly facilitating recruitment and resource allocation. In Agile however, HR plays a central role. Agile is completely based on people skills and team dynamics. The success of Agile depends on the proactive and strategic role of HR. Before joining an Agile project environment, HR professionals themselves must become agile. Kreissl (2012) argues that "incorporating (the four values of agile development, namely) adaptability, transparency, simplicity and unity can help improve HR service delivery".

A stated in the Agile Manifesto, the first and foremost principle of Agile is that we must value individuals and group interactions over processes and tools, which means that any processes introduced should facilitate empowerment and encourage social interactions. HR needs to focus on building an organisational climate and culture that explicitly encourages creative thinking and autonomous work groups. In Agile, HR's role starts with working on transforming the organisational culture to ensure a change of mind set from conventional project management to Agile. As all the HR functions are interrelated, the entire people management system, from recruitment to on boarding to performance and reward management, needs to be aligned to the new work culture.

Underscoring the critical role of HR in the implementation of Agile, Gieles \& van der Meer (2017, p. 2) state that

"The role of HR in an Agile world is to facilitate and improve organizational Agility and increase talent motivation. This implies: effectively changing the HR's mission and role to the more coaching and serving role of talent-specialists. This (is) in contrast to the traditional way, where the job of HR is mostly seen as implementing controls and standards to drive execution". 
Organisational Culture: The most essential prerequisite for success of Agile in an organisation is conducive organisational culture. It is not easy for an organisation which was hitherto working on traditional methods to transform itself to agile processes without radically altering the culture prevailing in the organisation. This transformation process is relatively slow and HR plays a critical role in making this happen. As change agents, HR professionals need to have a personal interaction with every member moving into agile mode and ensure that they are attitudinally fit to take up the new roles. The learning and development function needs to take a major responsibility to familiarise everybody in the organisation with agile principles, starting from top management right down up to the team member level through appropriate training programmes. These training programmes must include both behavioural training and training on agile methods and principles. They should systematically work to build a culture of openness, trust and honesty in the organisation through continuous engagement of all stakeholders.

Talent Management: HR plays a key role in proactively staffing and managing the entire talent ecosystem in an agile organisation. Considering that Agile teams are self-organised and cross functional, there is no need for micro managing them and in fact, micromanagement could be counter-productive. Having recruited talent with the right mind set and competencies for Agile, HR should promote motivation and higher morale among the people by offering them a chance to challenge themselves through complex projects, creating platforms which provide continuous learning opportunities, by ensuring proper work life balance and creating ownership. Growth of employees will be the key to retention and this can be ensured only through transparent and flexible career graphs.

A well-oiled HR analytics model can keep HR managers to predict likely changes and help them to handle the same proactively. A clear understanding of the skills requirement (both behavioural and technical) would help HR to contribute towards improving Agility. A good on-boarding process, allocation on challenging projects and continuous evaluation on how they feel makes the employees feel important and engaged in an agile system.

Gieles \& van der Meer (2017, p. 23) believe that 'talent management is the beating heart of an agile organisation' and to visualise this analogy, developed the HR->T Model (see Figure 4.2) consisting of the following five components:

1. Talent Organization (planning and organization) 
2. Talent Acquisition (recruitment and selection)

3. Talent Management (compensation, performance, training and development)

4. Talent Data (collection and analysis of data)

5. Talent Strategy (proactive changes and innovative ideas).

Insert Figure 4.2 somewhere here

As stated by Gieles \& van der Meer (2017, p. 7 and 10) "Like the heart, the talent team beats in a steady rhythm (Agile way of working). It receives impulses from the outside world and from different parts of the organization, so it can react and speed up or slow down as needed ... Any agile way of working is a short-cyclic, iterative and feedback-driven way of working". HR must try and create an innovative and people focussed talent ecosystem driven by the power of data analytics which continuously works towards improving its service levels on the basis of feedback received from the operations team

Recruitment \& Selection of Agile Teams: HR's role in building an agile organisation begins with attracting the right talent with the right attitude and mindset (Mahajan, 2013). The internal and external impulses in the T model indicate demand and availability of talent. HR teams need to plan talent acquisition strategies appropriately with more emphasis on attitudinal aspects. Along with Intelligence Quotient (IQ) and the technical skills, the talent acquisition team needs to look at Emotional Quotient (EQ) and Adversity Quotient (AQ). It should also assess the candidate's ability to collaborate and turn obstacles into opportunities. It is crucial to find alignment between vision, mission and values of the candidate, with that of the organisation before a candidate is on-boarded.

Each role in an agile team is customised and as such needs specific skills (technical, behavioural and managerial) to successfully deliver the project on time, within budget and to customer specifications. The Product owner should have astute business skills with overarching knowledge of business goals and vision of the customer's organisation. He/she should be able to clearly articulate the vision to the team and provide a clear roadmap on how best to achieve this and effectively address all the impediments on the way. The Scrum 
master should essentially be a servant leader. Attitudinally, he/she should be a go-getter and should be adept in relationship building and diplomatic skills. The development team members should be good in interactive skills, collaboration and should be able to put team success above their individual success.

HR teams supporting Agile projects must maintain a detailed record of both technical skills and behavioural skills of employees observed through various team building and other group activities so that they can provide the right person for the right role at the right time. As reiterated by Gothelf (2014), “(in an agile organisation) HR teams need to start hiring for creativity, collaboration and curiosity. They need to seek out the non-conformists - the candidates that don't easily fit into a box. These are the generalists with an entrepreneurial spirit”.

Table 4.3 summarises the key skills and competencies required in agile personnel.

Insert Table 4.3 somewhere here

Competency Development: In Agile environment, HR teams must focus towards continuously reskilling and reorienting the workforce to suite dynamically changing business needs. The learning and development system should be redesigned to promote design thinking and innovation. Continuous learning and development must be integrated into dayto-day working of the teams. The effort should be towards building a 'learning organisation'. Table 4.4 provides the design thinking principles of learning organisations as proposed by three leading thinkers in the field, namely, Senge, 1990, Morgan (1997) and Marsick \& Watkins (2003).

In Distributed Scrum, some of the stakeholders of the project are geographically separated from the other members. In many cases, the separated team members belong to different cultures, and speaking different languages. Since trust and communication are the backbone for success of Agile, HR needs to work on ways and means of developing trust among disparate team members through appropriate policies and practices. Bridging the cultural gaps is a very critical requirement in distributed agile and HR must leave no stone unturned to ensure this happens. 
Performance Management: Considering that agile teams are self-managed, traditional methods of performance management by the managers will not be effective. Several organisations have customised their own performance management models with 360 degrees feedback loop befitting their organisational priorities, environment and culture. We explain below how this can be done.

The Performance Appraisal of Team Members may be done at four levels as below:

Level 1:

Appraisal By Self ( S)

Level 2:

Appraisal by Peers (Average Value) (P)

If $\mathrm{P}-\mathrm{S}<1$, consider $\mathrm{S}$

If $\mathrm{P}-\mathrm{S}>1$, ignore $\mathrm{S}$

Level 3:

Appraisal by Scrum master / Coach (M1)

Level 4:

Appraisal by Product Owner (M2)

Final Rating:

Case 1: if $\mathrm{P}-\mathrm{S}<1$,

$(\mathrm{S}+\mathrm{P}+\mathrm{M} 1+\mathrm{M} 2) / 4$

Case 2: if $\mathrm{P}-\mathrm{S}>=1$

$(\mathrm{P}+\mathrm{M} 1+\mathrm{M} 2) / 3$

The Performance Appraisal of Scrum Master may be done as below:

Level 1:

Self-Appraisal - S

Level 2:

Average of Appraisal by team members - T

Level 3:

Appraisal by Product Owner - P

Initial Rating:

$(\mathrm{S}+\mathrm{T}+\mathrm{P}) / 3$, if $\mathrm{T}-\mathrm{S}<1$ 
$(\mathrm{T}+\mathrm{P}) / 2$, if $\mathrm{T}-\mathrm{S}>1$.

Rewards and Recognitions (R\&R): Since Agile wants to bind its employees emotionally, a properly designed and transparent rewards and recognition (R\&R) system is essential. An incorrectly designed R\&) system could be counterproductive in an Agile environment. Unlike in traditional systems, where managers decide R\&R for the people, in Agile, the teams are self-organized in deciding who amongst them should be rewarded. The usual process followed is that at the end of each sprint retrospective, the team members are asked to give preferential votes for star of the team award and the final decision is made on the basis of team's preference. All other recognitions should be team based on the basis of the entire team performance rather than any individual's contribution. Apart from financial rewards, social recognition rewards are equally valued in an agile project environment.

According to Gothelf (2017), while the technology teams may embrace Agile way of working,

"they often find that the pace of work they desire is substantially hindered by the lack of agility in HR ... In an agile organisation, HR needs to provide the same services it's always provided - hiring, professional development, performance management - but in ways that are responsive to the ongoing changes in the culture and work style of the organisation".

While reiterating how HR drives the agile organisation, Silverstone, Tambe \& Cantrell (2015, p. 12) conclude

"As agility becomes the new mantra of business, organizations will reshape themselves so that they can fluidly pull resources when and where they're needed to rapidly respond to changing business conditions. HR organizations of the future will have to reinvent themselves - and the HR and talent management practices they support - to drive agility in their organization. Those that fail to do so may put their organizations at risk of obsolescence".

\section{Implementation Challenges to Agile Project Management}

While Agile way of working has been offered as a solution to the inertia and rigidity inherent in traditional IT projects, such as waterfall methodology, leading to their inability to address volatile business environments, the implementation challenges to Agile projects remain the same as they require the project team members 'to drastically change their work habits and 
acquire new skills' (Chan \& Thong, 2009, p. 803). Overcoming employee resistance to change is the biggest challenge to organisations that attempt to radically change their organisational culture. According to Burchardi et al. (2016, p. 1) "companies across many industries are struggling with the transition to Agile ... (because, primarily) it is not easy to integrate self-directed, cross-functional Agile teams into the existing hierarchy of large companies".

Research studies that examine technology adoption perspective, such as Technology Acceptance Model (TAM), typically focus on technology characteristics (for example, perceived usefulness and ease of use) and overlook non-technology factors relating to employee ability, motivation and opportunity (AMO). In implementing Agile philosophy, organisations need to pay special attention to 'ability-related factors (eg., self-efficacy), motivation-related factors (eg., voluntariness) and opportunity-related factors (eg., shared understanding) (Chan \& Thong, 2009, p. 812).

Dyba \& Dingsoyr (2008, p.850) conducted a systematic review of empirical studies of agile software development and identified several benefits and limitations. They found that agile development practices thrive in radically different environments, are easily adoptable and yield better code quality, customer and employee satisfaction. The limitations are that they

- Are more suitable for small teams than for larger projects

- Work best with experienced development teams

- Not pay enough attention to design and architectural issues, and

- Require high levels of individual and team autonomy, interpersonal skills and trust Organisational transformation starts from the top and that's where the problem with Agile implementation often begins. According to Rigby, Sutherland \& Takeuchi (2016),

"(untrained) executives launch countless initiatives with urgent deadlines rather than assign the highest priority to two or three. They spread themselves and their best people across too many projects ... They talk more than listen ... They routinely overturn team decisions. With the best of intentions, they erode the benefits that agile innovation can deliver".

Another difficulty with agile method is that it underplays the importance of 'documentation' causing junior development team members raise too many questions to senior developers 
delaying the delivery of iteration and potentially increasing the development cost. Further, the 'short time frame allocated to each iteration' makes it difficult for developers to meet tight deadlines. Agile requires excellent social and interpersonal skills from team members, most of whom are technical specialists with poor understanding of the dynamics of informal workplace socialisation (Leau, Loo, Tham \& Tan (2012, p. 164-166).

According to Misra, Kumar \& Kumar (2009), some of the key success factors in adopting agile software development practices are: customer collaboration, customer commitment, decision time, corporate culture, personal characteristics, societal culture, and training and learning. As these factors require enterprise-wide culture change, many firms will struggle to meet the transformational expectations.

\section{Summary}

While IT projects are technology intensive, most projects fail due to non-technical reasons, including lack of agility in requirement handling and absence of customer involvement. Agile methods came into being to overcome these challenges and to exploit the power of empowerment, motivation, self-management, team dynamics and fully participating customer. However, all these special characteristics of Agile require successful adoption of 'learning organisation' (Senge, 1990) with sweeping change in organisational culture, elimination of command and control managerial mindset, servant leadership and selfmanaging teams, which is a tall order, to say the least. It also requires HR to strategize the agile eco-system and play a central role in making Agile successful.

That said, agile way of working is a must for any organisation operating in a fast changing, volatile, uncertain, complex and ambiguous (VUCA) global business environment with rising customer expectations to do more with less (time and money). Even though Agile thinking originated in software development, organisations can leverage its immense potential across all the core business units, including HR (Sherman, Edison, Rehberg \& Danoesastro, 2017). As "Agile development is an exercise in continuous improvement (and) not a one-off exercise" (Burchardi et al. (2016, p. 5), it is all about mindset, not methodology and is a journey, not a destination. 


\section{Case Study: Manager's Role in Sustaining Agile Team Performance}

A 300 million USD, 2 year IT project at John Neilson Software Limited, Australia, was to be delivered in Agile Scrum. Jessica, HR Director, had trained the team to be truly selforganising. Moses, the Scrum Master and originally a micro-manager, was coached, with the help of an external counsellor, to be more of a mentor and coach for the team.

After the third sprint, when team motivation and ownership picked up, Jessica proceeded on a six month maternity leave after suggesting to the management to put in a replacement. But the management felt that since things had stabilised and under control, they will be able to manage without HR member till Jessica returned. In the $9^{\text {th }}$ Sprint round, the team ran into unexpected difficulties. Two critical members got into a big verbal duel and stopped collaborating. One of the key members resigned unexpectedly which had a telling impact on the output and it went significantly behind plan. Moses was unable to resolve the situation and he particularly missed Jessica's guidance. His first instinct was to withhold the bad news from the customer.

One day, the Vice President of the business group Mr. Raymond ventured into the team's work area and by looking at the information radiators realized that the team was significantly behind plan. He asked for an explanation. Moses responded that the team encountered some challenges and trying hard to get on track. Raymond retorted, "Moses you are aware that this project is highly critical. We can't let it fall behind. As a Manager, you have to ensure that the team delivers and fully obeys your instructions. From now on, I want you to take charge of every aspect of the project and make sure that we remain on track".

Confused, Moses responded, "Raymond, we had decided to deliver the project the agile way and let the team be self-organised. Our frequent interference could only be counterproductive". Raymond had been too busy to attend in-house agile training. The HR team had mailed him a slide deck on agile principles, self-organising teams and the new role for managers. But he didn't seem to have gone through the information pack. He said, "Well, while the team may be responsible, I will hold you accountable if anything goes wrong. It's YOUR job to make it happen."

In response, Moses got back to his micromanagement style and demanded to know from the team who had done what, what is left out and why. As the sprint progressed, Moses got more 
and more involved. Daily stand-ups got converted to update meetings. The team members who were earlier excellent performers became disengaged. Team motivation and morale suffered. No one seemed to be interested in any original thinking. The team changed itself into a submissive mode. At the Sprint Review, Raymond personally turned up and was quite happy to see that somehow the team met the sprint objective and generously complimented Moses.

Upon hearing this, everyone in the team decided not to stick their neck out in the subsequent sprints. As the sprints progressed, Moses got more and more involved in micromanaging the team, self-organisation was conspicuous by its absence, team morale and motivation took a dip and the productivity fell to an all-time low. Team communication broke down and those amazing initial sprints where the team was bubbling with motivation and performing beyond expectations had become more of a distant memory. The project went deep into red and Raymond was puzzled what went wrong.

\section{Case Study Questions}

1. Identify the key implementation challenges faced by the team in the case study, using the 12 Agile Principles.

2. Using the case study, explain the critical role played by HR in Agile way of working.

3. Based on the lessons learnt from the case study, identify the key success factors in an Agile environment. 


\section{Debate: What is the key to project management success - agility or stability?}

\section{Introduction}

One of the continuing challenges in the management discipline is how to achieve the right balance between managerial control and creative freedom. The industrial economy was dominated by command and control management style that somewhat suited the relatively stable business environment. However, the present knowledge economy which is characterised by rapid change and uncertainty demands employee agility, autonomy and empowerment so that knowledge workers are free from stifling bureaucratic controls. In the IT project management domain, Waterfall or structured methodologies dominated for many decades. However, market dynamics and competition and ever evolving new technologies led to the emergence of Agile methods. It is still hotly debated as to whether Agile can be considered as "cure all" challenges in technology project management.

\section{Arguments in favour of Stability}

- Stability helps maturity of development processes guaranteeing sustainability, repeatability and replicability of results, project after project.

- Stability provides ease of controlling and monitoring budgets and schedules which are critical for technology projects.

- Stability offered by structured methods provides ample scope for skilling of new resources.

- Stable methods are very apt for fixed price/ budget projects.

- Large projects spanning long duration are best delivered using the structured models.

- Detailed documentation helps project managers in overcoming challenges created by employee attrition. It also helps in easier maintenance after project goes live.

\section{Arguments in favour of Agility}

- All requirements can never be frozen at the beginning of any project in a dynamic business environment. Agility is the only answer under such conditions.

- Empowerment and flexibility offered by agility promotes innovative spirit in the team members, leading to better project outcomes.

- Continuous delivery of potentially shippable software, iteration after iteration helps business in deriving market advantage of frequent releases 
- Agility makes pre-closure of projects (if required due to business imperatives) easy which is not possible with structured models

- Sizable reduction in documentation promoted by agile methods helps the teams to concentrate more on working software.

\section{Useful References:}

Aghina, W., De Smet, A. \& Weerda, K. (2015). Agility: It rhymes with stability.

McKinsey Quarterly, December 2015. https://www.mckinsey.com/businessfunctions/organization/our-insights/agility-it-rhymes-with-stability

Austin,R. D. (2007). CMM Vs Agile: Methodology wars in Software Development Harvard Business Review Case Study. PRODUCT \#: 607084-PDF-ENG

Boehm, B. \& Turner, R. (2004). Balancing agility \& Discipline: A guide for the perplexed. Boston: Pearson Education

Orr, K. (2011). CMM versus Agile Development: Religious Wars and Software Development. Executive Report, Vol. 3, No. 7. The Ken Orr Institute. https://issuu.com/kenorr/docs/apm0702

\section{Video Learning Resources}

- Agile Project Management: Scrum \& Sprint Demystified https://www.youtube.com/watch?v=DvBKevrItcc

- Agile Simulation - Meet the Agile Team: https://www.youtube.com/watch?v=hgn_oNmfTqg

- Agile Simulation - The Daily Standup: https://www.youtube.com/watch? $\mathrm{v}=\mathrm{q}$ R $9 w Q Y 4 G 5 I$

- Kotter's 8 Change Model: https://www.youtube.com/watch?v=jKXuTMfcO5c

- What is Change Management? https://www.youtube.com/watch?v= IlYNMdV9E 


\section{References}

Burchardi, K., Hildebrandt, P., Lenhard, E., Moreau, J. \& Rehberg, B. (2016). Five secrets to scaling up agile. Bcg.perspectives. Boston Consulting Group. http://imgstg.bcg.com/BCG-Five-Secrets-to-Scaling-Up-Agile-Feb-2016 tcm9-87077.pdf

Chan, F. K. Y. \& Thong, J. Y. L. (2009). Acceptance of agile methodologies: A critical review and conceptual framework. Decision Support Systems, 46: 803-814.

Dyba, T. \& Dingsoyr, T. (2008). Empirical studies of agile software development: A systematic review. Information and Software Technology, 50: 833-859.

Gieles, H. \& van der Meer, W. (2017). Talent management as the beating heart of an Agile organisation. https://www.scrum.de/wp-content/uploads/2017/11/prowarenesswhitepaper-agile-talent-hannekegieles.pdf

Gothelf, J. (2014). Bring agile to the whole organisation. Harvard Business Review. 92(11): November 14, 2014.

Hastie, S. \& Wojewoda, S. (2015). Standish Group 2015 Chaos Report: Q\&A with Jennifer Lynch. InfoQ. https://www.infoq.com/articles/standish-chaos-2015

Kreissl, B. (2012). What is agile human resources? Canadian HR Reporter. http://www.hrreporter.com/columnist/hr-policies-practices/archive/2012/04/24/whatis-agile-human-resources/

Leau, Y. B., Loo, W. K., Tham, W. Y. \& Tan, S. F. (2012). Software development life cycle AGILE vs traditional approaches. 2012 International Conference on Information and Network Technology (ICINT 2012), IPCSIT, Vol. 37, p. 162-167.

Mahajan, A. (2013). The importance of HR in agile adoption. Scrum Alliance.

https://www.scrumalliance.org/community/articles/2013/january/the-importance-of$\underline{\text { hr-in-agile-adoption }}$

Marsick \& Watkins (2003): Dimensions of Learning Organisation Questionnaire, Advances in Developing Human Resources, 5(2):132-151

Misra, S.C., Kumar, V. \& Kumar, U. (2009). Identifying some important success factors in adopting agile software development practices. Journal of Systems and Software, 82(11): 1869-1890. 
Morgan (1997): Images of Organisation, Thousand Oaks: Sage

Rigby, D. K., Sutherland, J. \& Takeuchi, H. (2016). Embracing agile. Harvard Business Review, May, 2016.

Senge, P. (1990). The Fifth Discipline, the Art and Practice of the Learning Organization. New York, NY: Doubleday/Currency

Sherman, M., Edison, S., Rehberg, B. \& Danoesastro (2017). Taking agile way beyond software. Boston Consulting Group. https://www.bcg.com/enau/publications/2017/technology-digital-organization-taking-agile-way-beyondsoftware.aspx

Silverstone, Y., Tambe, H. \& Cantrell, S. M. (2015). HR Drives the agile organisation. Accenture Strategy. https://www.accenture.com/t20160913T220140_w_/usen/ acnmedia/Accenture/ConversionAssets/DotCom/Documents/Global/PDF/Strategy_3/Accenture-Future-of-HR-TrendsAgile-Organizations.pdf

VersionOne (2016). 10 $0^{\text {th }}$ Annual State of Agile Report. https://www.versionone.com/about/press-releases/versionone-releases-10th-annual$\underline{\text { state-of-agile-report/ }}$ 
Table 4.1: Principles of Agile Methodology

1) "Our highest priority is to satisfy the customer through early and continuous delivery of valuable software.

2) Welcome changing requirements, even late in development. Agile processes harness change for the customer's competitive advantage.

3) Deliver working software frequently, from a couple of weeks to a couple of months, with a preference to the shorter timescale.

4) Business people and developers must work together daily throughout the project.

5) Build projects around motivated individuals. Give them the environment and support they need, and trust them to get the job done.

6) The most efficient and effective method of conveying information to and within a development team is face-to-face conversation.

7) Working software is the primary measure of progress.

8) Agile processes promote sustainable development. The sponsors, developers, and users should be able to maintain a constant pace indefinitely.

9) Continuous attention to technical excellence and good design enhances agility.

10) Simplicity--the art of maximizing the amount of work not done--is essential.

11) The best architectures, requirements, and designs emerge from self-organizing teams.

12) At regular intervals, the team reflects on how to become more effective, then tunes and adjusts its behaviour accordingly." 
Table 4.2: Key Terms in Agile Scrum

Source: Authors

1. Product backlog: It is a prioritized list of all features that are required to be developed to achieve the business objective. It is highly dynamic and open to any changes as per the business needs.

2. Product Owner: Product owner is the customer or their representative with complete business vision and goals of the project. The customer owns the product backlog and decides the prioritization of goals and activities.

3. Sprint: This is a time-boxed period, at the end of which the team delivers a potentially shippable feature. The sprint periods may vary anywhere between one week to six weeks.

4. Scrum Master: He/she is the servant leader for the team and has three specific roles:

a. To protect the team from external disturbances

b. To resolve any problems / challenges that the team may be facing

c. To ensure scrum processes and ceremonies are meticulously followed

5. Development Team: This is the group of people who actually deliver the output to customers. In Agile, development teams are self-organised and cross functional.

6. User Stories: They are a customer's way of explaining their requirements.

7. Definition of Done: It is a shared understanding among all stakeholders about what "Done" means.

8. Scrum Ceremonies: To make scrum process effective and to ensure inspection, transparency and adaptation throughout, some essential ceremonies are introduced. These ceremonies include a sprint planning meeting, daily stand-up meeting, sprint review meeting and sprint retrospective meeting.

9. Scrum of Scrums: When several scrum teams scale up to work together on the same project, it is called Scrum of Scrums arrangement. One member of each team participates in an additional meeting called Scrum of Scrums meeting, where they discuss interdependencies among various teams and brief each other on work completed and work planned for the future.

10. Information Radiators: To ensure transparency, all information about product backlog, sprint backlog, work completed, work in progress, etc is displayed along the Agile Rooms. These boards are normally called Information Radiators as they give complete information on the project. 
- Adaptability to fast changing organisational and project requirements

- Alignment/fit between individual and organisational goals (shared commitment)

- Ability to work effectively in an autonomous, self-managing team environment

- Self-leadership and servant leadership

- Lifelong learning attitude and with an open mind

- Innovative \& creative mindset (Out of the box thinking)

- Entrepreneurial spirit

- Professional and customer-centric work ethic

- Spirit of cooperation and collaboration

- Personal mastery (desire to excel)

- Emotional intelligence

- Cross-cultural and cross-functional competence in a diverse environment

- Ability and motivation to work on challenging projects in a volatile, uncertain, complex and ambiguous (VUCA) global business environment

Source: Authors 
Table 4.4: Design Thinking Principles of Learning Organisations

\begin{tabular}{|l|l|l|}
\hline Senge (1990) & Morgan (1997) & Marsick \& Watkins (2003) \\
\hline - Systems thinking & - Build whole into parts & - Create continuous learning \\
- Personal mastery & - Importance of redundancy & opportunities \\
- Mental models & - Requisite variety & - Promote enquiry \& dialogue \\
- Shared vision & - Minimum specs & - Encourage collaboration \& team \\
- Team learning & - Learn to learn & learning \\
& & - Create (IT) systems to capture \& \\
& & share learning \\
& & - Empower people toward a collective \\
& & vision \\
\hline
\end{tabular}

Source: Authors 
Figure 4.1: Agile Scrum Process Diagram

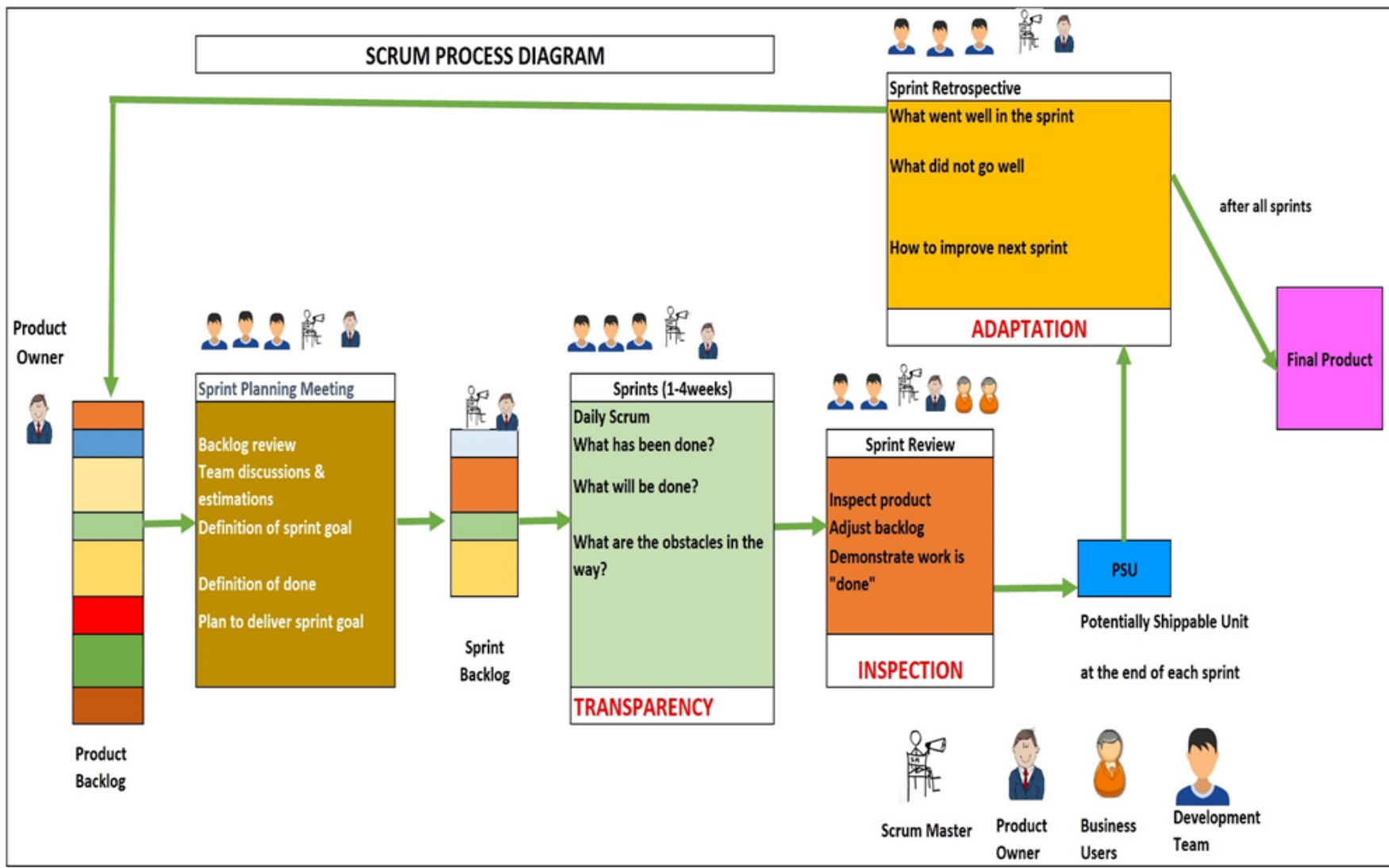

Source: First Author 
Figure 4.2: Gieles and van der Meer's HR->T Talent Management Model Under Agile

Source: Gieles \& van der Meer (2017, p. 26): Reproduced with permission.

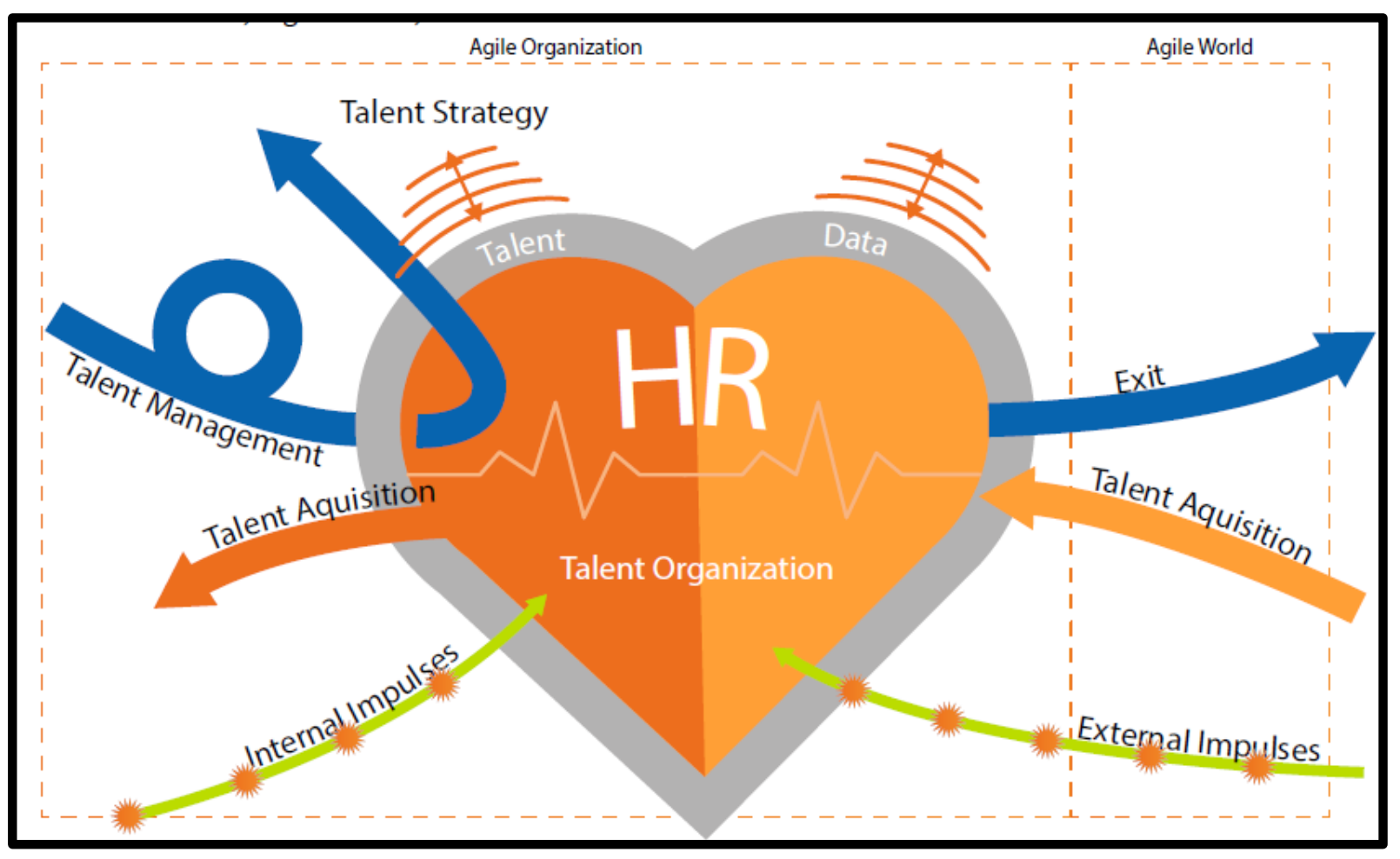

